Faculdade de Ciências Econômicas UFRGS
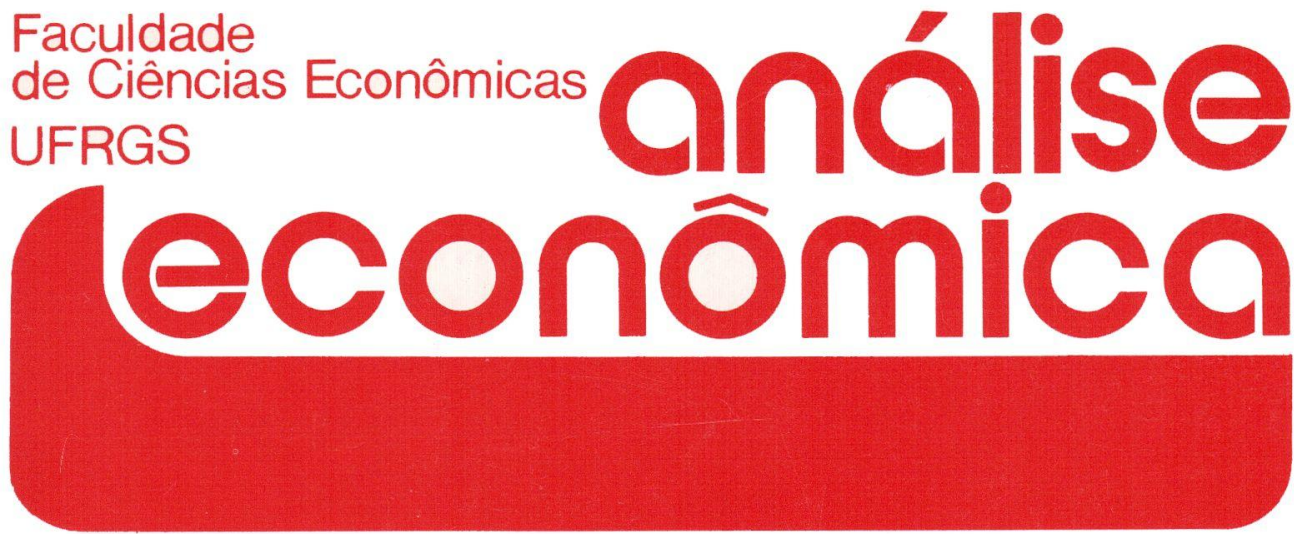

- INDEXAÇĀo SALARIAL: UMA ABORDAGEM MACROECONÓMICA Jo Anna Grav

- AJUSTE NO EMPREGO E PRODUTIVIDADE NA DECADA DE OITENTA

Carlos Antônio Luque José Paulo Zeeteno Chahad

- O CONSUMIDOR KEYNESIANO Marcelo Córtes Neri

- HETEROGENEIDADE DO TRABALHO E TAXA DE LUCRO EM MARX

Francisco Cribari Neto

- ECONOMIAS DE ESCALA: UMA REVISĀO Jesiel de Marco Gomes

- Concentraçấo bancária no BRASIL

Marcelo Resende

- NOYOS RUMOS PARA O SETOR ELETRICO NO BRASIL

Adriano Pires Rodrigues

Eduardo da Cunha Vianna

- OFERTA E DEMANDA DE FRANGO DE CORTE NO BRASIL

Narciso Gonçalves de Castro et alii

- ANÁLISE ECONÔMICA DA IRRIGAÇÃo DO MILHO

Lúcia M Schirmer

Juvir Luiz Mattuella

- REFLORESTAMENTO NO BRASIL. Carlos José Caetano Bacha

- ESCOLHA DE TECNOLOGIA EM ESTRUTURA DE PRINCIPAL AGENTE Kyle D. Kauffma:

- A QUESTÁo DEMOGRÁfica e A PRAXEOLOGIA

Anton Karl Biedermann et alii
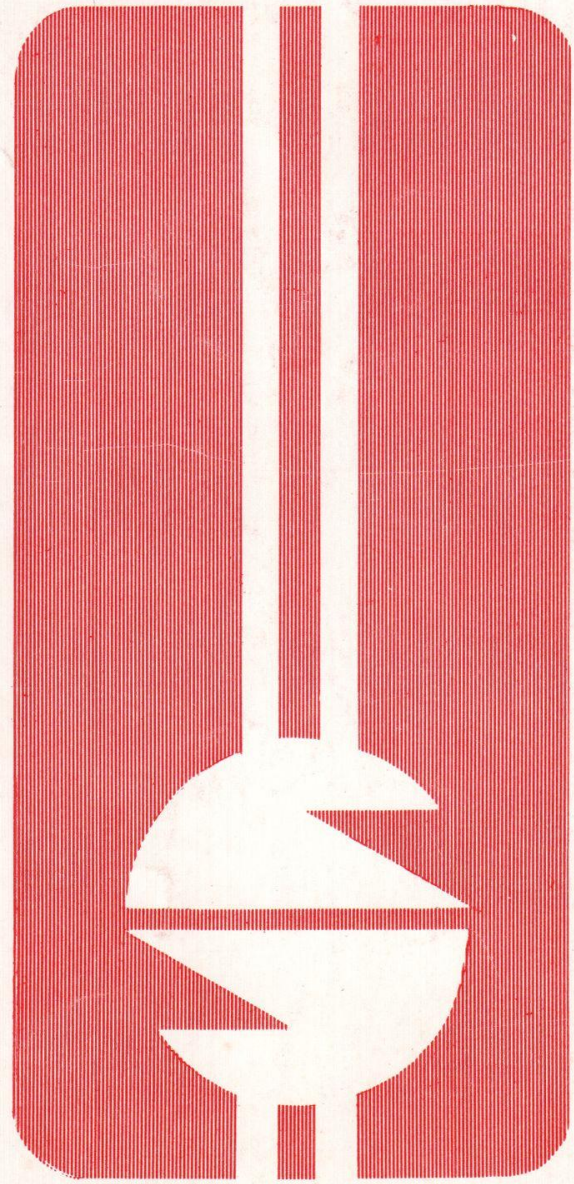
UNIVERSIDADE FEDERAL DO RIO GRANDE DO SUL

Reitor: Prof. Tuiskon Dick

FACULDADE DE CIÉNCIAS ECONÔMICAS

Diretora: Prof ${ }^{\text {a }}$ Yeda Rorato Crusius.

CENTRO DE ESTUDOS E PESQUISAS ECONÔMICAS

Diretor: Reinaldo Ignacio Adams

DEPARTAMENTO DE CIÉNCIAS ECONÔMICAS

Chefe: Prof. Fernando Ferrari Filho

CURSO DE POS-GRADUAÇÄO EM ECONOMIA

Coordenador: Prof. Nali de Jesus de Souza

CURSO DE PÓS-GRADUAÇĀO EM ECONOMIA RURAL

Coordenador: Prof. Atos Freitas Grawunder

CONSELHO EDITORIAL: Achyles Barcelos da Costa, Aray Miguel Feldens, Atos Freitas Grawunder, Carlos Augusto Crusius, Ernani Hickmann, João Rogério Sanson, Juvir Luiz Mattuella, Maria Imilda da Costa e Silva, Nali de Jesus de Souza, Nuno Renan Lopes de Figueiredo Pinto, Otilia Beatriz Kroeff Carrion, Otto Guilherme Konzen, Paulo Alexandre Spohr, Pedro Cezar Dutra Fonseca, Reinaldo Ignacio Adams, Roberto Camps Moraes, Valter José Stülp, Yeda Rorato Crusius, David Garlow (Wharton Econometrics Forecasts Association, E.U.A.), Edgar Augusto Lanzer (UFSC), Eleutério F.S. Prado (USF), Fernando Holanda Barbosa (FGV/RJ), Gustavo Franco (PUC/RJ), Joaquim Pinto de Andrade (UnB), Juan H. Moldau (USP), Werner Baer (Univ. de Illinois, E.U.A.).

COMISSĀO EDITORIAL: Atos Freitas Grawunder, Pedro Cezar Dutra Fonseca, Reinaldo Ignacio Adams e Roberto Camps Moraes.

EDITOR: Nali de Jesus de Souza

SECRETARIA: Maria Ivone de Mello (normalização), Vanete Ricacheski (revisão de textos).

FUNDADOR: Prof. Antônio Carlos Santos Rosa

Os materiais publicados na revista Análise Econômica são de exclusiva responsabilidade dos autores. É permitida a reprodução total ou parcial dos trabalhos, desde que seja citada a fonte.

Aceita-se permuta com revistas congêneres. Aceitam-se, também, livros para divulgação, elaboração de resenhas ou recenșões.

Toda correspondência, material para publicação, assinaturas e - permutas devem ser dirigidos ao seguinte destinatário:

\section{PROF. NALI DE JESUS DE SOUZA}

Revista Análise Econômica

Av. João Pessoa, 52

CEP 90040-000 - PORTO ALEGRE (RS), BRASIL

Telefones: (051) 228-1633 - 224-6024 ramais 3440 e 3348

Fax: (051) 225-1067 


\title{
ECONOMIA DE ESCALA: UMA REVISÃO SOBRE AS TEORIAS TRADICIONAL E MODERNA DOS CUSTOS E SUA ADEQUAÇÃO AO MUNDO REAL
}

\author{
Jesiel de Marco Gomes*
}

\section{SINOPSE}

Este trabalho examina o conceito de economias de escala e sua associação com a função de produçäo, produtividade, etc , bem como as teorias disponíveis sobre o formato das curvas de custo: Conclui que a moderna teoria das custos 6 mais adequada ao mundo real, porque a empresa pode minimizar seus custos dentro de um intervalo de produçảo, que permite maior flexibilidade em função das contingèncias do mercado.

\section{INTRODUÇĀO}

É absolutamente corriqueiro nos cursos de economia, particularmente nas disciplinas ligadas a chamada teoria dos preços, entediar os alunos com suposições, conceitos e teorias completamente irreais do ponto de vista do sistema econômico capitalista. Um exemplo disso é o abusivo uso do tempo no estudo de mercados de concorrência perfeita ou pura. Mais grave do que isto $e$ abordar a teoria dos custos na forma neoclássica convencional (custos médios e marginais em forma de $(U)$. Principalmente porque este estudo quando aplicado ao conceito de economias de escala (um componente da eficiência econômica - objetivo preconizado por qualquer sistema econômico) somente pode também ser "aplicado" do ponto de vista de uma fictŕcia economia de concorrência perfeita.

Sabidamente no mundo capitalista, uma das características fundamentais é a folga no uso de plantas (não pleno emprego, portanto). Isto é

* Professor da Universidade Federal de Santa Catarina.

\begin{tabular}{|l|l|l|l|l|}
\hline ANÁLISE ECONÔMICA & ANO 10 & NN 17 & MARÇO/92 & P.59-88 \\
\hline
\end{tabular}


devido (dentre outras razóes), de um lado, à incerteza e à formação de barreiras à entrada e, de outro, à necessidade de ordem ideológica e econômica (Kalecki, 1983). Por isto, é inaceitável que o empresário possua apenas um ponto de otimização de custos.

Como falou-se acima, o objetivo de qualquer sistema econônico $\varepsilon$ o da eficiência. Uma forma de medir a eficiência é verificar a existência ou não de ganhos de escala. Sabidamente os ganhos de escala estão associados aos custos médios de longo prazo e, em conseqüência, às formas de tais custos. Portanto, ao estudar-se economias de escala, passase, necessariamente, pelo exame de pertinência das teorias que buscam analisar a formação de custos. Por esta razão, o presente estudo tern por finalidade:

a) examinar o conceito de economias de escala e a associação com outras categorias (produção, processo produtivo, funçāo de produção, produtividade e caminho de expansão);

b) examinar as teorias disponfveis que determinam o formato das curvas de custo, particularmente a de custo médio de longo prazo, por estar intimamente associada ao conceito de economias de escala.

Os objetivos acima expressos serão examinados dentro de um marco conceitual preponderantemente neoclássico.

\section{O CONCEITO DE ECONOMIAS DE ESCALA NO CONTEXTO DA TEORIA ECONÔMICA}

O presente item trata de conceituar e explicar as economias de escala. Como é do conhecimento especializado, esta categoria de análise está associada a outras, particularmente na tecria da produção e custos. Esta é a razāo porque procura-se conceituá-las, examinando todas, ainda que de modo sumário.

Entende-se por economias de escala, associadas a um bem em particular, a redução do custo médio de longo prazo (de prod'ução e de distribuição), à medida que se eleva o nível de produção. É basicamente uma relação entre custos médios e nível ou volume de produção, entendidos os dois últimos como escala ou tamanho de produçăo.

O primeiro trecho da curva de custo médio (decrescente) caracteri$\mathrm{za}$ as economias de escala. O segundo trecho desta mesma curva (crescente), assinalaria a existência de deseconomias, ocasionando descontroles gerenciais, os quais sobrevêm quando se expande a escala de produção. Isto implica perda de eficiência das unidades produtivas de grande porte (Guimarães/1983). A questão da hipótese de rendimento decrescente de escala, do ponto de vista do mesmo autor, $\hat{e}$ antes uma condição necessária de equilíbrio em um modelo de concorrência perfeita do 
que um pressuposto que reflita as condições reais do sistema produtivo Este ponto, aliás, foi exaustivamente abordado por Sraffa (1982) Dentre outras colocações, o autor refere-se a que a lei dos rendimentos não proporcionais foi elaborada tomando como ponto de partida a fusão da lei dos rendimentos decrescentes (teoria da renda da terra em Ricardo) com a lei dos rendimentos crescentes. Esta proveniente da especialização e da divisão do trabalho, (possibilitadas por plantas de maior porte) e inerente à noção de progresso técnico em A. Smith. A preocupação fundamental desta fusão - que "tomou leis fora do contexto teórico original" - foi discutir a formação de preços em concorrência perfeita e, neste contexto, buscar uma curva de oferta simetrica à de demanda. Todavia, Sraffa, ao levantar a hipótese de concorrência perfeita, aceita a lei dos rendimentos crescentes e admite-as como originárias das economias internas das unidades de produção. Quanto à lei dos rendimentos decrescentes, coloca-a em suspeita pela condição de manutenção de um fator fixo, dado que ele raciocina no longo prazo, quando todos os fatores de produção são considerados variáveis.

Como parece 6 bvio, o conceito de economias de escala, aqui tratado analogamente como economias internas ou ganhos de escala, decorre da produção. A produção é entendida como "a transformação intencional de bens ou serviços em outros bens ou serviços" (Simonsen/1971). Quando se tratar de um único produto, denomina-se produção simples; quando de vários, produção múltipla. No mundo real pode-se efetivar a produção através de técnicas que combinam qual (quais) a(s) quantidade(s) de fator(es) 1 que é(são) necessária(s) para obter dada quantidade de produto(s). A isto denomina-se processo produtivo técnico, método de produção ou atividade. Sinilarmente ao conceito de produção, o processo produtivo pode ser simples ou múltiplo. O acervo de processos produtivos existentes em uma sociedade, em um dado tempo, para a produção simples ou múltipla dos difereiıtes bens ou serviços, constitui-se no que simplesmente se denomina tecnologia disporível (Lancaster/1972).

Quando um processo produtivo utiliza o mesmo tipo de fatores, produz o(s) mesmo(s) bem(ns) ou serviço(s), de algum processo existente, mas se faz uso de menores quantidades de alguns (ou de todos), ou deixa de usar alguns, ou menos de alguns, porem mais de outros, para produzir determinada quantidade de bem(ns) ou serviço(s), diz-se que houve mudança tecnológica. Similarmente pode utilizar fatores de produção anteriormente não usados e produzir bem(ns) ou serviço(s) antes não produzidos.

1 O termo fatores de produção, ou fatores produtivos, $\ell$ aqui utilizado para designar os bens ou serviços parcial ou totalmente transformados no decorrer da produção, a exemplo de Simonsen (1971). 
Um processo ou (combinação de) é tecnicamente mais eficiente para uma dada produção de bem(ns) ou serviço(s), quando utiliza uma parcela menor de pelo menos um fator, relativamente a outro processo (ou oombinação dele). Ou, dito de outra forma, quando com o mesmo fluxo (estoque) de fatores produz mais de pelo menos um bem ou serviço, sem diminuir o de algum outro (Simonsen/1971).

Fica claro que situações como as descritas acima denotam o conceito de eficiência técnica. No caso de dois ou mais processos (ou combinações) em que são utilizados menos de um e mais de outro(s) fator(es), diz-se que tais processos (ou combinações deles) são igualmente eficientes do ponto de vista técnico. Aqui, evidente que está implícito o suposto que o empresário proceda de modo racional (dispondo-se a usar menos fatores de produção ao invés de mais). No caso de processos igualmente eficientes, a decisão quanto a qual processo adotar depende da relação de preços dos fatores. Trata-se, neste caso, da eficiência econômica ou eficiência-preço ou ainda eficiência alocativa (Koutzoyanis/1977 e Hall \& Leveen/1978). A eficiência econômica global ê runção de ambas: eficiência técnica e eficiência-preço. Uma unidade de produção só $\varepsilon$ amplamente eficiente sob a ótica econômica (eficiência global) se minimizar custo por unidade de produto (Hall \& Leveen/1978).

Como foi visto mais acima, com freqüência existem vários processos, os quais permitem o mesmo nível de produto, a partir de diferentes quantidades de fatores de produção. Quando se trata de identificar o processo que melhor utiliza uma dada quantidade de fatores, o conceito de função de produção é a ferramenta em geral empregada. Assim, define-se a função de produção como a relação que informa o "quantum" que se pode obter de um ou mais produtos, dada uma quantidade de fatores. Mais, precisamente, a função de produção trata de identificar o processo conhecido capaz de permitir o máximo de pzoduto, dada uma quantidade de fatores. Analiticamente, pode-se expressar $X=f(S 1, S 2, \ldots, S n)$, sendo $X$ o produto e $S 1, S 2, \ldots, S n$, os fatores. Como e possível que uma dada combinação de fatores permita uma vasta série de diferentes níveis de produção, vale ressaltar que o que interessa, então, é o produto máximo. Em coñseqüência, este produto máximo representa a produção eficiente do ponto de vista técnico, não ainda economicamente.

É interessante notar que, na noção de processo produtivo, a relação de dependência é oposta à prescrita na função de produção. Ou seja, como já referido acima, um processo indica quanto de' cada fator é necessário empregar para alcançar uma dada quantidade de produto. Uma função de produção determina o máximo de produto que se pode alcançar a partir de dada quantidade de fatores, através da seleção de 
processos (ou combinação de) eficientes.

$O$ conceito de função de produção examinado até o momento esteve associado a processos estáticos ${ }^{2}$, caso de produção simples. Este conceito pode ser ampliado para produção múltipla. Em tal circunstância, entende-se como funçāo de produção a relação que a dada combinação de fatores $\left(S_{1}, S_{2}, \ldots S_{n}\right)$ associa o conjunto das combinações eficientes de produto $\left(X_{1}, X_{2}, \ldots, X_{n}\right)$ que podem ser alcançados. Formalmente ela pode ser expressa como: $z=\left(X_{1}, X_{2}, \ldots, X_{n}\right)=f\left(S_{1}, S_{2}, \ldots, S_{n}\right)$.

Analogamente à produção simples, uma combinação eficiente de produto é aquela - respeitada a disponibilidade de fatores - em que se torna impossfvel aumentar a quantidade de qualquer um dos produtos, sem diminuir a de outro.

Quando se trata de situaçōes estáticas ${ }^{3}$, a função de produção pode assumir basicamente três tipos, segundo a natureza da substituição entre os fatores produtivos.

O primeiro tipo compreende a função de produção com fatores substitufveis. Neste caso, existe um número infinito de processos para a obtenção de dado produto, de modo que os fätores possam ser continuadamente substiturdos entre si. A situação de serem continuadamente substitufveis permite a diferenciação em todos os pontos. Analiticamente pode-se estabelecer dois exemplos deste tipo de função:

a) funçōes de produção lineares tipo:

$$
X=a S_{1}+b S_{2} \text { (seja a e b constantes); }
$$

b) função Cobb-Douglas homogênea:

$X=K S_{1}^{\alpha} S_{2}^{l-\alpha}$ (sendo K e $\alpha$ constantes e,

$$
o\langle\alpha(1\rangle \text {. }
$$

Dada a existência de uma infinidade de processos, $\epsilon$ possível que, no setor agrícola, haja um melhor ajuste destas funções.

No caso da ocorrência num único processo produtivo, tem-se uma função de produção com fatores limitativos. Assim, dadas as quantidades de fatores, cada uma delas irá limitar a quantidade máxima de produto a ser obtida. Deste modo, suponha-se que a produção de $X$ seja obtida a partir dos fatores $S_{1}$ e $S_{2}$, cujos coeficientes técnicos $\alpha_{1}$ e $\alpha_{2}$ expres-

\footnotetext{
2 o que, em geral, costuma ocorrer no mundo real, pois bá sempre um lapso de tempo entre a utilizaçăo de fatores e a obtenção do produto. Inobstante esta ressalva, uma descriç5̆o estática pode permitir unı razoável aproximação da realidade.

3 O caso mais geral de processos dinâmicos, bem nais complexo, não será aqui abordado.
} 
são a proporção necessária da cada fator. Então, dadas as quantidades $S_{I}$ e $S_{2}, S_{1} / \alpha_{1}$ e $S_{2} / \alpha l_{2}$, são as limitaçōes de produção de $X$, respectivamente, quanto aos fatores $S_{1}$ e $S_{2}$.

Analiticamente, esta função de produção com fatores limitativos e expressa $\mathrm{X}=\min \left(S_{1} / \alpha_{1}, S_{2} / \alpha_{2}\right)$, podendo ocorrer uso pleno ou excesso de um ou de dois fatores disponfveis.

As indústrias químicas seriam os exemplos de uso de tais funções de produção. Todavia, há algumas possibilidades de substituição de fatores quando se tratar a indústria como compreendendo também serviços auxiliares de produção.

Um terceiro e último tipo de função estática de produção é a que realiza combinações de um número finito (maior que um) de processos. Ela É denominada de combinação de processos. E $E$, em verdade, um tipo intermediário entre os dois casos referidos acima e que deve descrever de modo mais realista a produção de certos setores industriais. A tftulo de exemplo, suponha-se que para produzir $X$ existam dois processos conhecidos, os quais utilizam os fatores $S_{1}$ e $S_{2}$. Os coeficientes técnicos do processo um são $\alpha_{1}$ e $\alpha_{2}$; os do segundo $\beta_{1}$ e $\beta_{2}$, respectivamente de cada um dos fatores de produção. Como as quantidades destes são dadas, elas vão se distribuir entre as duas técnicas (processos) de modo a se alcançar o máximo de produto. $O$ problema de dados $S_{1}$ e $S_{2}$ determinar o máximo de $X$ e resolvido via técnica de programação linear, a qual se resume em: maximizar $X=X_{1}+X_{2}$, (sendo $X_{1}$ e $X_{2}$, respectivamente as produções correspondentes a cada um dos processos), sob as condiçóes:

$$
\begin{aligned}
& \alpha X_{1}+\beta_{1} X_{2} \leqslant S_{1} \\
& \alpha X_{1}+\beta_{2} X_{2} \leqslant S_{2} \\
& X_{1} \geqslant 0 ; X_{2} \geqslant 0
\end{aligned}
$$

Fixados os três tipas estáticcó de função de produção, vale parcialmente acrescentar que, para cada tipo de problema, é possível idientificar o tipo de função de produção conveniente, como afirma Simonsen (1971). Ele afirma tamberm que a discussão se torna mais sutil quando os fatores ou produto apresentam "certo tipo de agregação" (grifc meu). A agregação de que trata o outro é aquela que funde em um único fator homogêneo os diferentes equipamentos (capital). Afirma a seguir que a substituição entre fatores é maior no longo que no curto prazo e ela $\epsilon$ mais ampla à medida que aumenta o nivel de agregação do fenômeno a ser estudado. Dar justifica porque, em nivel de uma econcmia global, é possivel estabelecer uma função de produção do tipo $Y=f(K, L)$, onde $Y$ e o produto nacional (a preços constantes), $K$ o estoque de capital e $L$ o volume de mão-de-obra. 
Em verdade, o problema não está exclusivamente na substituição maior ou menor entre os fatores. Aliás, o próprio Simonsen admite isso quando usou a expressão discussão "sutil para certo tipo de agregação". O problema fundamental se encontra na transformação dos diferentes equipamentos em um único somente, via agregação monetária. Assim, o conceito se torna um "conjunto de mecano", geléia, manteiga, aço, milho, etc (Lima/1974). Em outras palavras, o problema relevante é o da mensuração do capital.

A mensuração do capital pode ser realizada com base no custo de produção incorrido 4 ou via lucros futuros ${ }^{5}$. A hipótese implícita dos neoclássicos no caso é de que o mundo é competitivo e sem incerteza, quando em equilíbrio. As duas formas de medida do capital levam a resultados equivalentes. Então, para determinar a taxa de lucro normal Faz-se mister, "a priori", conhecer o valor da produtividade nominal do capital e, portanto, o do estoque de capital, do qual esta última depende. Finalmente e entretanto, para se conhecer o valor do estoque de capital, E necessário antes ter conhecimento da taxa de lucros (Lima/1974). Isto, como pode perceber, evidencia um racioć́nio tipicamente circular e, em conseqüência, insolúvel.

Complementando como afirma J. Robinson6, citada por ( $\mathrm{Li}-$ ma/1974), para estabelecer a função de produtividade toma-se como dada a taxa de lucros ou lucro normal e pretende-se como propósito da função de produção justamente mostrar como os salários e a taxa de juros são determinados pelo desenvolvimento tecnológico e pelas proporçōes dos fatores.

Diante do exposto, pode-se concluir que a ressalva básica quanto a funções de produção, está ligada sobretudo a suas implicações de natureza distributiva (entre trabalho e capital).

A distribuição do produto, segundo neoclássicos e "neoclássicos" far-se-á de acordo com a relação capital/trabalho $(K / L)$. Quando ela tende a aumentar, aumentará a produtividade marginal da mão-de-obra e reduzirá a do capital, o que, por sua vez, iusplicará aumento dos salários. Quando a relação $(K / L)$ diminui, ocorre o contrário. Para J. Robinson?, segundo Lima (1974), "nẩo faz sentido pensar em um processo de acumulação como um processo ao longo de uma função de produção, de baixas relaçôes $K / L$ para relações mais elevadas, independentemente do

\footnotetext{
4 Salários pagos aos trabalhadores. Gastos com materia-prima e a taxa de juros ou de lucro manual sobre o valor da matéria-prima e do estoque de capital, utilizados na produçtio.

5 Neste caso, 9 valor do capital expresso por: $K=P_{1} / l+r^{2}+\ldots+P_{n} / 1+r^{n}$; sendo $K$ o capital; $P$ o lucro por periodo e $r$ a taxa de lucro.

6 Robinson, J. The Function and the Theory of Capital. In: Harcourt \& Laing, 1953.

7 Robinson, Joan, Capital Theory up to Date. In: Hunt \& Schwrtz, 1990.
} 
progresso técnico".

No disposto até aqui, considerou-se uma função de produção contemplando fatores sob controle das unidades de produção. Vale dizer, considerou-se a possibilidade de ocorrência das chamadas economias internas. Considere-se agora uma função de produção do tipo: $X=f\left(S_{1}, S_{2}\right.$ $\left., \ldots, S_{n}, X_{1}{ }^{\prime}, S_{1}{ }^{\prime}, S_{2}{ }^{\prime}, \ldots, S_{n}{ }^{\prime}\right)$, onde os termos, após o ponto e vírgula, correspondem a efeitos externos. Em tal situação admite-se que uma variedade de produção/ou um agregado (qualquer delas) está sujeita também à economias ou deseconomias externas técnicas. Ou seja, depende da produção ou da compra/venda de fatores por outras empresas. Ou, dito de outro modo, uma variedade de produção (ou conjunto delas) depende apenas da quantidade de fatores por ela absorvidos. Porem, esta dotação pode ser modificada pela operação de outras unidades de produção (Simonsen, 1971). Por esta razão, tal circunstância pode implicar acréscimo ou diminuição nos custos monetários de longo prazo. E conveniente ressaltar que isto implica uma alteração da função-custo, ou seja, da curva de custo a longo prazo. Por exemplo, no setor agrícola, condições locacionais em relação a mercado de fatores e de produtos ou condiçōes diferenciadas de clima e solo etc. podem propiciar diferentes níveis de custo para iguais tamanhos de plantas, localizadas em regiōes diferentes.

Em resumo, o conceito de função de produção, vale reafirnuar, originalmente prende-se à relação entre quantidades físicas máximas de produto(s) associado(s) a dada dotação ffsica de fatores. $O$ que, aliás, é irreprimivel.

Quando se trata, porem, de transformar quantidades ffsicas em valores, via preço, para homogeneizá-las, tentando tornar o conceito operacional, as questões se complicam. Até mesmo porque "os dados disponíveis para estudos empíricos muitas vezes o são em forma de valor de produção e de valor de insumos" (Lancaster/1972).

Inobstante as restric̄es referidas, as funções de produção são de uso generalizado e podem permitir comparação de desempenho entre setores ou subsetores. Isto ocorre tanto no pafses de economia descentralizada como nos de economia centralmente planificada, do ponto de vista da ação do Estado. É preciso, particularmente em nosso pars, que se perceba a ampla bibliografia exisiente a este respeito com origem em pafses centralmente planificados. Assim é que, pelo menos em duas publicações soviéticas, verifica-se o amplo uso de funçōes de produção (Dobrini/1982 e URSS/1981). Aliás, $\in$ interessante registrar que, na publicação soviética "Planificación de la Economia Nacional", o conceito de função de produção compõe um glossário. Onde afirma que $\boldsymbol{\epsilon}$ a equação que reflete a relação estável com o objetivo de modular (por exemplo uma empresa, um ramo de economia racional em seu conjunto), entre o mon- 
tante de produção e os gastos para obtê-la.

No âmbito do presente item, até o momento, examinou-se conceitualmente economias de escala e alguns dos demais conceitos (produção, processos produtivos e função de produção) que ajudam a compreendê-lo.

Percorrendo esta trajetória, em seguimento, faz-se necessário estabelecer alguns dos instrumentos básicos de análise da produção, parte dos quais terão aplicação neste trabalho. Os instrumentos a serem abordados serão: a produtividade média, a produtividade marginal, as isoquantas, o cámintuc de expansão e, finaln rente, os corrceitç de custo e suás formats.

Define-se a produtividade: média ou produto médio $(P i)$ como a relação entre a quantidade de produto obtida $(X)$ e a quantidade do fator considerado $(S i)$. Isto $E, P i=X / S_{i} . O$ emprego deste conceito contem uma limitação. A de que, obviamente, a produtividade média de um fator depende não apenas da quartidade alocada deste. Depende tc milḱm cias quantidaces empregadas des de:rrais fatores ${ }^{8}$. Além distc, a procutividade média, quando ccinte mpla o preço dos produtos e/ou o valor cos fatores ou dos serviços dos mesticis (considerada comos unı fndice farcial e estático de eficiência (Fialho \& Maia, 1983) apresenta limitacóes adicionźis de outra ordem. Para Fourestier (196C), a produtividade mı́dia assim é denominada indireta im contrefrcisição à produtividade física, a qual é direta e essencialmerte técriç.

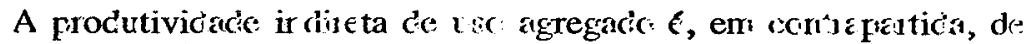

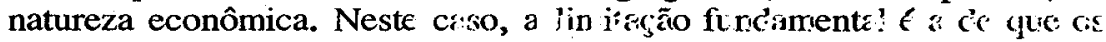
preços dos bens e/ou serviços variam com a própria produtividade. Razão porque, a solução estaria na busca de um sistema de preços constantes.

Por produtividade marginal de um fator entende-se o acréscimo no produto, obtido quando se utiliza uma unidade adicional deste fator, mantidas constantes as quantidades dos demais.

As figuras 1, 2 e 3 abaixo, respectivamente, demonstram as formas t́picas: a) da curva de produção em função das diferentes quantidades de um fator, mantidas constantes as dos demais; b) a curva de produtividade marginal, em função das quantidades desse fator, mantidas constantes as quantidades dos demais; e c) curva de produtividade média de um fator, em função das quantidades empregadas desse, mantidas constantes as quantidades dos demais fatores. É evidente que, nos três casos acima, trata-se do curto-prazo. No longo prazo, todos os fatores são considerados variáveis.

Em função de produção diferenciais análogas à Fig. 1, pode ser

8 Admite-se que uma funçăo de proc'uçăa, por consideror todos cs fatores empregados, proporciona a obtençåo de um f́ndice de eficiếncia global, e năo parcial. 
comprovado (o que não se fará aqui) que produtividade média no seu ponto máximo, se iguala à produtividade marginal de dado fator. Isto é perfeitamente verificável graficamente, pois quando a produtividade média $\varepsilon$ inferior à marginal, uma unidade a mais de produção eleva a média e, vice-versa.

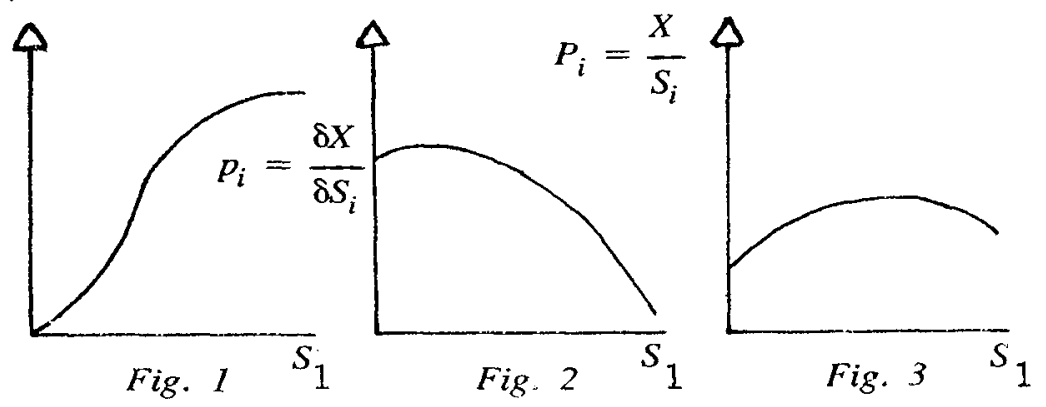

Outro conceito que se relaciona com escala e particularmente com a noção de função de produção ê o de isoquanta. Uma isoquanta ou curva de isoprodução transmite uma parte das informações contidas na função de produção. Denomina-se isoquanta o lugar geométrico das combinações das diferentes quantidades de fatores que permitem um dado nrvel de produto. Dado o conceito de isoquanta, $\varepsilon$ facilmente constatável que, nesta noção, está contida a noção de processo produtivo. No caso são diferentes quantidades de fatores que permitem um dado nível de produto. Entāo, esta noçāo contém um número de processo que variam de um ao infinito, dependendo da disponibilidade entre os fatores.

Se, de um lado, a noçãc de isoquanta transmite parte das informaçôes contidas na função de produção, de outro, um mapa de isoquanta (ou grupo delas) transmite todas as informaçōes contidias na função de produçāo, pois estabelece todas as ccimbineções de fatores possiveis a cada produção máxima. Em conseqüência, a noção de função de produşão, dar obtida (máximo de produto), contempla a escolha de um ou uma única combinaçāo de processo eficiente, a cada nfvel máximo de produto obtivel, dadas as quantidades dos fatores.

As isoquantas ou mapas delas assumem formas variadas em função do númelu de processos produtivos disponiveis. Estes, por sua vez, caracterizam a relaçâo de substituiçāo entre os fatores ${ }^{9}$ utilizados em cada processo produtivo.

Em um limite ter-se-ia um mapa de isoquantas na forma de um ângulo reto (Fig. 4). Esta situação corresponde a uma função de produção

$9 \mathrm{Um}_{\mathrm{m}}$ conceito extremamente utilizado $\varepsilon$ a taxa de substituição entre os fatores $T M g S$, e decorre de compraraçóes entre processos produtivos. Neste caso. a razão $\left(\delta S_{1}\right) /\left(\delta S_{2}\right)$ e desconifnu: . Para funçठes contínuas (infinitos processos a $T M_{g} S=\delta s_{2} / \delta S_{1}$. 
com fatores limitativos. Neste caso, a produtividade marginal de cada fator e nula. Um outro exemplo seria um mapa de isoquantas com formatação poliangulares, ( $\mathrm{Fi}_{\mathrm{i}}$. 5) às quais correspondem a combinação de dois ou mais processos produtivos. Ar, a partir de certa quantidade de fator $\left(S_{1}\right.$ ou $\left.S_{2}\right)$, a produtividade marginal é também nula.

Um mapa de isoquanta retilínea, negativamente inclinada (Fig. 6) corresponde a fatores perfeitamente substiturveis de tal modo que poderse-ia obter qualquer nf́vel de produção com apenas um fator.

Em tal caso, a produtividade marginal de ambos é constante e a taxa marginal de substituição igualmente.

Deve-se notar que os caso representados pelas Figuras 5 e 6 pertencem a situações intermediárias.

Finalmente, isoquantas convexas em relação à origem dos eixos correspondem a fatores substitufveis.
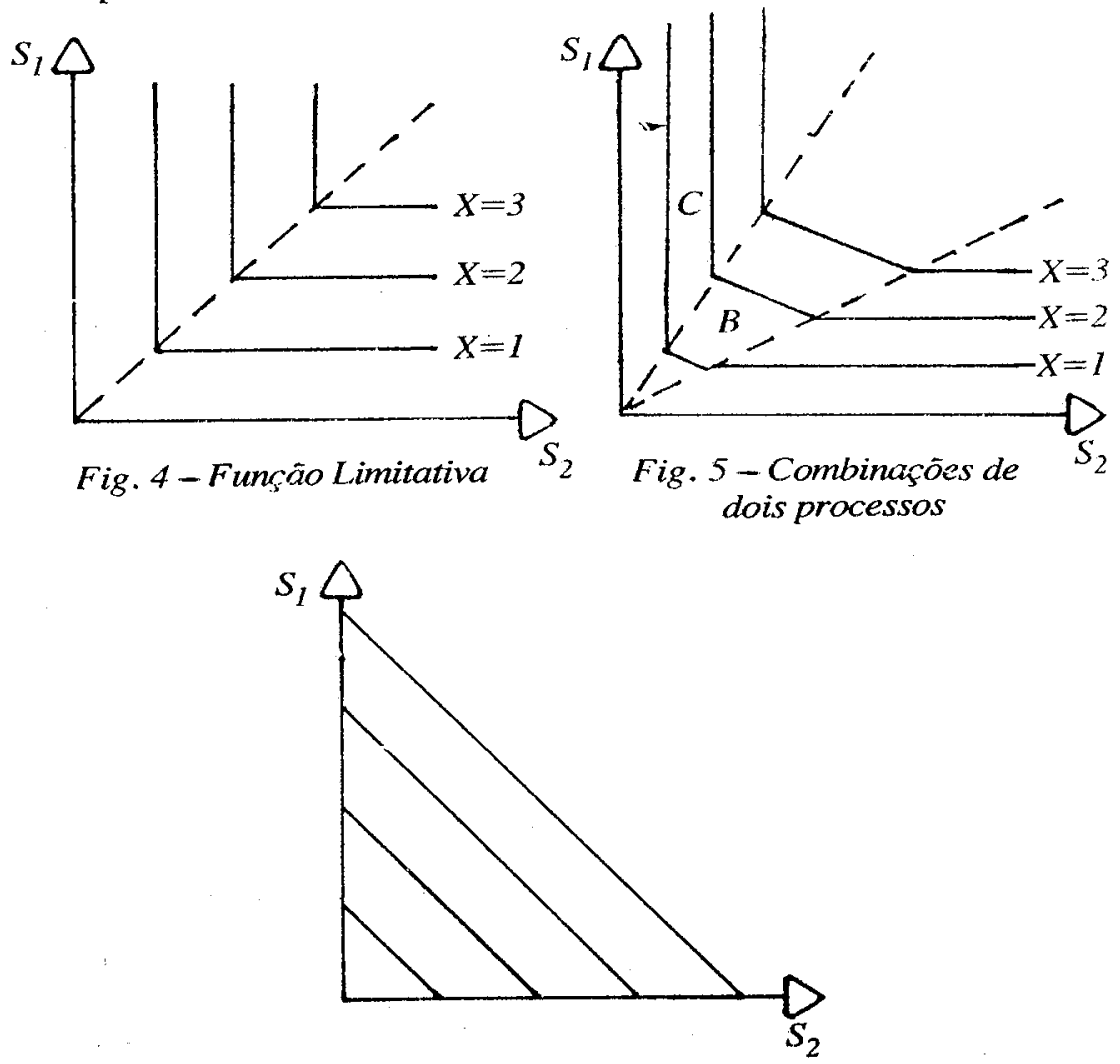

Fig. 6-Substituição Perfeita 
Uma maneira alternativa de visualizar-se a questão dos rendimentos ffsicos obtidos é através de mapas de isoquantas. Quando as isoquantas se distanciam umas das outras de modo igual (Fig. 7) 6 o caso de rendimentos constantes, onde dobra a quantidade de todos os fatores duplicando a quantidade do produto. Quando o espaço entre as isoquantas se torna progresivamente menor à medida que aumenta a produção (Fig. 8) estará refletindo o caso de rendimentos crescentes. Ar, duplica a quantidade de fatores e mais do que dobra a quantidade de produto. Finalmente, quando as isoquantas se afastam progressivamente entre si denota-se o caso de rendimentos decrescentes (Simonsen/1971).
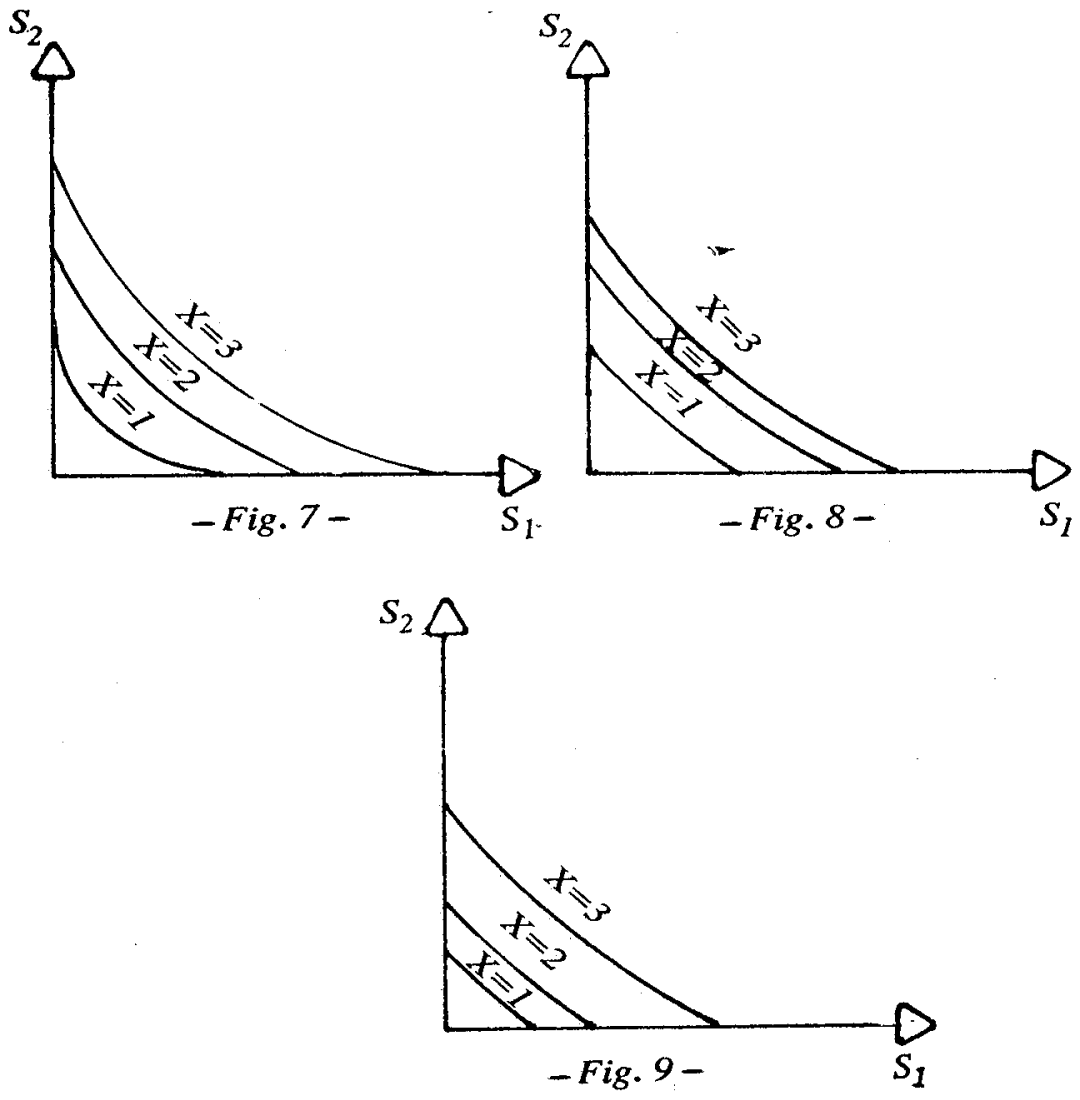

A questão da associação dos mapas de isoquanta aos rendimentos, particularmente aos rendimentos constantes de escala levantada ante- 
riormente, remete ao importante axioma da homogeneidade na teoria da produção. Por ele, admite-se que todo o processo de produção (exceção à questão das indivisibilidades dos fatores) é homogêneo de grau um. Isto constitui-se em um corolário da homogeneidade. $O$ princf́pio da homogeneidade está contido num postulado cientffico muito geral. $O$ de que "uma experiência repetida em condiçōes idênticas deve dar resultados também idênticos". Aplicado à teoria da produção, significa admitir que, se um processo é duplicado, os resultados também serão duplicados.

Um cenário do princípio da homogeneidade é o de que qualquer mapa de isoquantas que possa ser descrito por sua função de produção estática envolvendo fatores divisíveis e que descreva todos os fatores necessários à obtenção do produto, deve ser homogênea de grau um. Ou seja, analiticamente:

$f\left(\lambda S_{1}, \lambda S_{2}, \ldots, \lambda_{n}\right)=Y f\left(S_{1}, S_{2}, \ldots, S_{n}\right)$, sendo $S_{1}, S_{2}$ e $S_{n}$ os fatores de produção e qualquer que seja $\lambda\rangle 0$. Ou seja, se os fatores sã̃o duplicados, implica a duplicação do nfvel de produção.

Este axioma, como assegura Simonsen (1971), parece colidir com a existência de rendimentos decrescentes e crescentes. Tal não ocorre ${ }^{10}$ :

a) devido a não disponibilidade de vários fatores de produção de uma variedade de produção (em nível de sociedade e mesmo de uma unidade de produção). Razão porque nem sempre $\epsilon$ possível duplicar a dotação de todos os fatores. Então, com a duplicação de apenas alguns fatores de produção é de se esperar que o nível do produto cresça em proporção menor (rendimentos decrescentes de escala);

b) porque os processos empregados para produzir $2 \times$ (sendo $X \circ$ produto) nem sempre poderão ser divididos ao meio para produzir $X$. Então, se $m$ que multiplica $X$ e um número inteiro, se alguns dos fatores são divisiveis e se a função de produção discrimina todos os fatores envolvidos, como por exemplo:

$f\left(m S_{1}, m S_{2}, \ldots, m S_{n}\right) \geqslant m f\left(S_{1}, S_{2}, \ldots, S_{n}\right)$, o que determina a compatibilidade do prinćpio da homogeneidade com rendimentos crescentes de escala.

c) e, finalmente, pois nem todas as atividades podem ser descritas por processos estáticos. É o caso de tarefas preparatórias que são realizadas quer se produza por pouco ou muito tempo.

Exemplo disto é a preparação à produção de um livro e, depois sua tiragem, cujo tempo pode ser alongado. Assim, é possível surgirem rendimentos crescentes de escala quando se produz por mais tempo.

Até aqui, examinou-se a produção quase que exclusivamente do

10 É corveriente referir que a), b) e c) correspondem, de certa form a, a uma aproxim nçáo dies fontes de escala. 
ponto de vista tecnico. Um problema de ordem fundamental (e que tem a ver com o objeto da análise dos economistas ${ }^{11}$ ) da teoria da produção se constitui, conhecidos os preços dos fatores, determinar qual a combinação dos mesmos que possibilitam um dado produto com um custo mínimo. Particularmente para a produção $\operatorname{com} n$ processisos, existem tecnicamente um número igual a $n$ de combinações de quantidades de fatores. A condição de minimização, um dos postulados da teoria econômica neoclásisica, transfere o problema da eficiência técnica para a eficiência econômica, as quais jâ foram definidas antes. Assim, se, analiticamente, se expressar a função de produção como $X=f\left(S_{1} S_{2}, \ldots, S_{n}\right)$ e se $\pi_{1}$ e $\pi_{2}$ os preços dos fatores, a questāo é formulada da seguinte forma: minimizar $\pi_{1} S_{1}+\pi_{2} S_{2}+\ldots+\pi_{n} S_{n}$, sob as condiçöes: $f\left(S_{1}, S_{2}, \ldots, S_{n}\right)=X^{\infty}$ (onde $X$ o é uma dada produção méxima) e $S_{1} \geqslant 0 ; S_{2} \geqslant 0 \ldots, S_{n} \geqslant 0$. Se a função de produção for diferenciável e os fatores sejam substituíveis, então, a condição de mf́nimo custo é obtida na utilização dos multiplicadores de Lagrange, através dos quais conclui-se que: $p_{1} / \pi=p_{2} / \pi_{2}=\ldots p_{n} / \pi_{n}$, onde $\mathrm{p}_{1}, p_{2}, \ldots, p_{n}$ representam as produtividades marginais de cada um dos fatores Ou seja, a condição de mínimo custo, para obter dada produçāo é de que deve-se combinar quantidades dos fatores de modo a que suas produtividades marginais sejam proporcionais a seus respectivos preços. A solução do problema pode ser ilustrada pela Fig. 10 e ela consiste em buscar o ponto de isoquanta $X^{\infty}$ que passa pela mais baixa das retas paralelas do isocusto. No ponto $P, p_{1} / p_{2}=\pi_{1} / \pi_{2}$, onde $\pi_{1} / \pi_{2}=t g$.
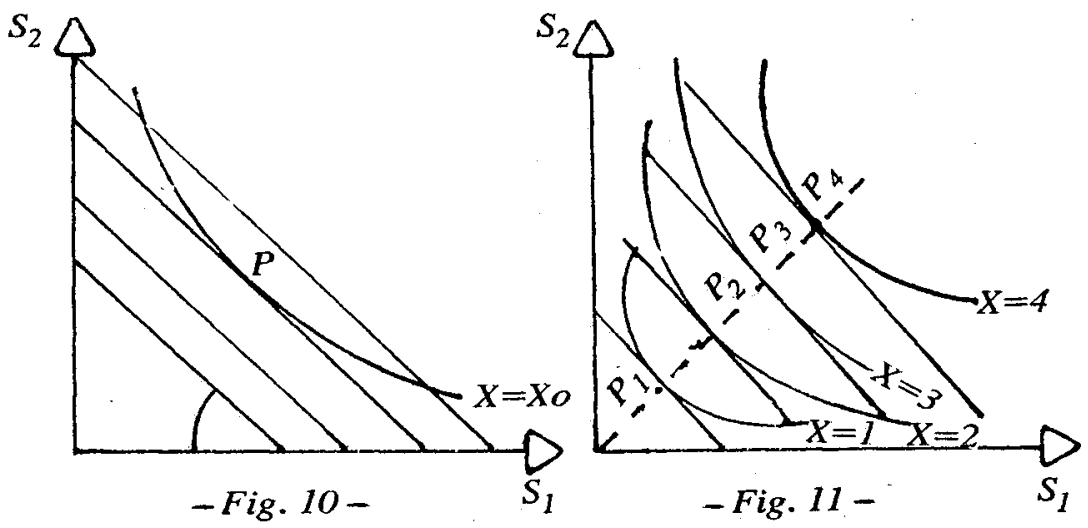

11 Propriedades de escala, de substituiçăo entre fatores, on de substituiçžo de produto ou de cuantidade procluzida (Simonsen, 1971). 
Acima, acabou-se de verificar o problema de minimização para uma dada produção. Ao se ter um conjunto de $n$ produções dadas, a cada uma delas haverá uma combinação de fatores que garanta tal produção com um mínimo de custo. Assim, é possfvel definir a função: $S_{1}=g_{1}(x)$, $S_{2}=g_{2}(x), \ldots, S_{n}=g_{(n)}(x)$, as quais indicam o "quantum" necessário de cada fator para obter um dado nfvel de produto, com custo mínirro. Designa-se caminho de expansão (Fig. 11) a curva definida por estas funçốes $\left(P_{1} P_{2} P_{3} P_{4}\right)$, a qual pressupóe, obviamente, o conhecimento do preço dos fatores produtivos.

\section{ECONOMIAS DE ESCALA E OS CUSTOS DE PRODUÇĀO: IMPORTÂNCIA, CONCEITO, DEFINIÇŌES E TEORIAS SOBRE O FORMATO DAS CURVAS OU CUSTOS $^{12}$}

\subsection{Importância}

O exame das categorias de análise associadas às economias de escala, concluiu-se, acima, com o caminho de expansão.

Como foi lá exposto, este conceito implica necessariamente o conhecimento dos preços, dos fatores de produção e, em conseqüência, os custos de produção. Esta é uma das razões por que vão-se examinar os custos. A segunda, mais fundamental, é porque - como se disse no início do tópico anterior - o conceito de escala está intimamente associado ao custo médio de longo prazo e $\epsilon$ decorrente dos conceitos de custo de produção. Aliás, por oportuno, e para reforçar a ulitima relação entre economias de escala e custo médio de longo prazo, as curvas correspondentes sãn também chamadas de curvas de escala (Bain/1963 e Guimarães/1983). Mais particủarmente, a questão da escala, dado que relaciona custos e niveis de produção ou capacidade de produção ou tamanho de planta, tem a ver com o formato das curvas de custo a médio, curto e longo prazos, ou da função a estas correspondentes.

Esta questão tem tambêm relevância no âmbito da teoria e da política econômica (Sraffa/1982), pois trata sobretudo da eficiência alocativa ou eficiência-preço a qual combinada com a eficiência técnica determinará a eficiência econômica, em nfvel estrito de custos. De modo geral o conhecimento das funçöes-custo-curvas de custo torna-se importante porque:

a) permite a tomada de decisóes pelas empresas e pelo setor governo;

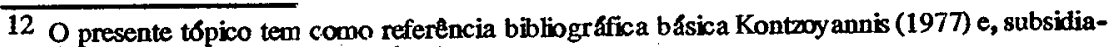
rirmente, Simonsen (1971), alem de outros autores. 
b) estabelecidas as funçōes custo de curto prazo, de longo prazo permitem informaçōes acerca das políticas planejadas de crescimento e investimento das empresas.

De modo particular pode-se alinhar várias situações que esclarecem a relevância do tema e que detalham melhor os itens a) e b) acima (Sraffa/1982):

i) Os custos têm papel reconhecidamente relevante na formação de preços (Kalecki/1983).

ii) Se, por exemplo, em um determinado setor os ganhos de escala são importantes, pode-se esperar que, este mercado, seja oligopolizado (Bain/1963). Logo, os custos definem a estrutura de mercado.

iii) Se as condições de crescimento de uma unidade produtiva forem determinadas pelos custos e seu custo medio tem a forma de " $U$ " então ela já teria alcançado o máximo de tamanho de planta viável. Assim, a empresa teria duas alternativas. A primeira repetir o tamanho da planta existente. A segunda, diversificar seus investimentos.

iv) Finalmente, para a definição de políticus de concentração ou desconcentração e fundamental identificar a existência ou não de ganhos de escala.

\subsection{Conceitos e definições}

As funções-custos são derivadas das funções de produção e descrevem os processos eficientes de produção em um dado perfodo de tempo (Koutzoyanis/1977). Portanto, o custo de produção de X, quantidade de um dado bem, $€$ o custo da combinação mais econômica, através da qual se pode obter tal quantidade de $X$. A curva de custo de produção expressa a despesa com a equisição de fatores ao longo do caminho de expansão (Simonsen/1971).

Distingue-se custos de curtc (CP) e longo prazo (LP). Consideramse os primeiros, aqueles ocorridos em um periudo de tempo tal que um ou vários fatores de produção são fixos. Em geral, admite-se que eștes são os equipamentos e administração. Os custos de longo prazo são aqueles que, durante um perfodo longo, há alteração em todos os atores de produção. Em suma, no curto prazo existe(m) fator(es) fixo(s); no longo, todos se tornam variáveis. Ássim, os custos de longo prazo são considerados "custo planejado" ou custo "ex-ante", pois seria af que o empresário escolheria entre um amplo rol de alternativas de investimentos (expressos pelos tamanhos diferentes de plantas), definidas pelo estado atual da tecnologia.

Analiticamente, a função-custo pode ser expressa: i) no caso do longo prazo: $C_{(x)}=f(X, T, P f)$ e, ii) no caso do curto prazo: 
$C_{(x)}=f(X, T, P f, K)$. Onde $C_{(x)}=$ custo de $X ; X=$ quantidade produzida de $X ; T=$ Tecnologia; $P f=$ preço dos fatores; e $K=$ fator(es) fixo(s).

É extremamente comum para facilitar a análise grafica em duas dimensōes, expressar assim os custos: $C_{(x)}=f_{(x)}$ "ceteris paribus", ou seja mantidos constantes os demais fatores que o afetam. A alteração nos fatores considerados constantes, portanto, implica mudança na própria curva de custo. De outro lado, quando apenas $X$ se altera, ocorrem movimentos ao longo da curva de custo. Ern verdade, como se viu acima, a curva de custo representa uma função multivariada (Koutzoyanis/1977). É importante voltar a ressaltar que as economias internas "constroem" as formas das curvas de custo médio a longo prazo e estão relacionadas a fatores sob algum nível de controle dentro das unidades de produção. Contrariamente, as economias externas são afetadas por fatores fora do controle das unidades de produção e se realizam por ações de outras unidades, no mesmo ou em outro setor. Elas, por seu turno, causam também uma alteração nas curvas de custo de curto e longo prazo. Vale dizer afetam a posição das curvas de custo.

Segundc Koutzoyanis (15.77), existem duas teorias que explicam os custos. A teoria tradicional e a por ele chamada de moderna teoria dos custos. Ambas têm a mesma vertente neoclássica. A última contesta a forma estrita em "U", das curvas de custo médio de curto prazo por considerá-la irrealista. Rejeita também a "curva envelope" (custo médio de longo prazo) ao não admitir que as deseconomias de escala decorram necessariamente da produção em grande escala.

Independente de taị discordâncias - as duas serão abordadas mais abaixo - ambas as eorias, de modo geral, concordam com os conceitos e definiçōes de custo.

Assim, os custos se classificam em fixos e variáveis. Então $C T_{(x)}=$ $C F+C V_{(x)}$, onde $C T_{(x)}=$ custo total de $X ; C F=$ custo fixo; $C V_{(x)}=$ custo variśvel de $X$.

Os custus fixos incluem: a) salários do pessoal administrativo; b) salários do pessoal de apoio à produção, mas pagos independente dela; c) depreciação de capital fixo; d) despesas com manutenção e depreciação de constrı̣ções civis; e) despesas cum manutenção de terras. Este item corresponde, no caso de indústrias, a terrenos onde elas estão implantadas; na agricultura corresponderia à manutenção da capacidade produtiva do solo; e f) lucro normal, incluindo as taxas de retorno sobre o capital e as de risco.

Os custos variáveis incluem:

a) despesas com matérias-primas; b) custos sobre o trabalho diretamente ligado à produção; e c) despesas de operação com o capital fixo.

Dos conceitos de custo total $\left(C T_{(x)}\right)$, custos fixos (CF) e custos variáveis $\left(C V_{(x)}\right)$, resultaram as definiçōes que sèguem: 
i) custo médio total ou unitário $C M_{(x)}=C T_{(x)} / X$;

ii) custo fixo médio $C F M=C F / X$;

iii) custo variável médio $C V H=C V_{(x)} / X$;

iv) custo marginal $C M g_{(x)}=C_{(x)} / X$, no caso de funçóes contŕnuas.

Pode ser também definido como a alteração no custo total, decorrente da variação em uma unidade de produto.

\subsection{As formas das curvas de custo na teoria tradicional: o que há de essencial}

\subsubsection{Custos de curto prazo}

Dado que os custos fixos (CF) independem do nivel de produção, eles são expressos graficamente como uma linha reta paralela ao eixo das quantidades (Fig. 12).

O custo variável $\left(C V_{(x)}\right)$ é representado, em geral, em forma de ur. " $S$ " invertido. Assim, ele reflete a "lei das proporçōes variáveis" ou dos rendimentos não proporcionais. Por esta lei (onde, bem-entendido, dado o curto prazo supōe-se pelo menos um fator fixo) no estágio inicial de produção, para dada planta ou tamanło, quanto mais um fator $\varepsilon$ empregadc, tanto mais sua produtividade aumenta. Neste Caso, o custo variável médio $\left(C V M_{C P(x)}\right)$ declina. Isto perdura até que seja alcançada a combinação ótima entre fatores fixos e variáveis. Além deste ponto, haveria excesso de fator(es) variável(eis), o que determina o declf́nio da produtividade média do(s) fator(es) variável(eis).

A adiçãó do $C F$ ao $C V_{(x)}$ define a curva de custo total $\left(C T_{C P(x)}\right)$. A forma dela $\hat{E}$, obviamente, a mesma do $C V_{(x)}$, porém com abscissa correspondente ao nfvel do $C F$.

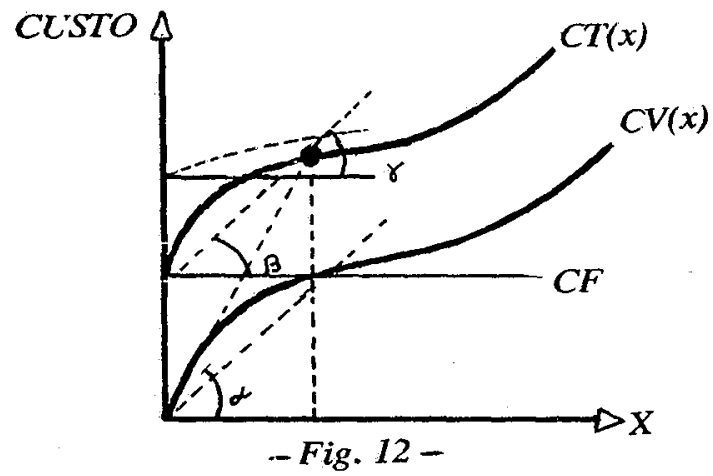


Como foi visto acima, das curvas de $C T_{C P(x)}$, obtêm-se as de $C M_{C P(x)}$ e de $C M g_{C P(x)}$. Os formatos destas curvas encontram-se na Fig. 13.

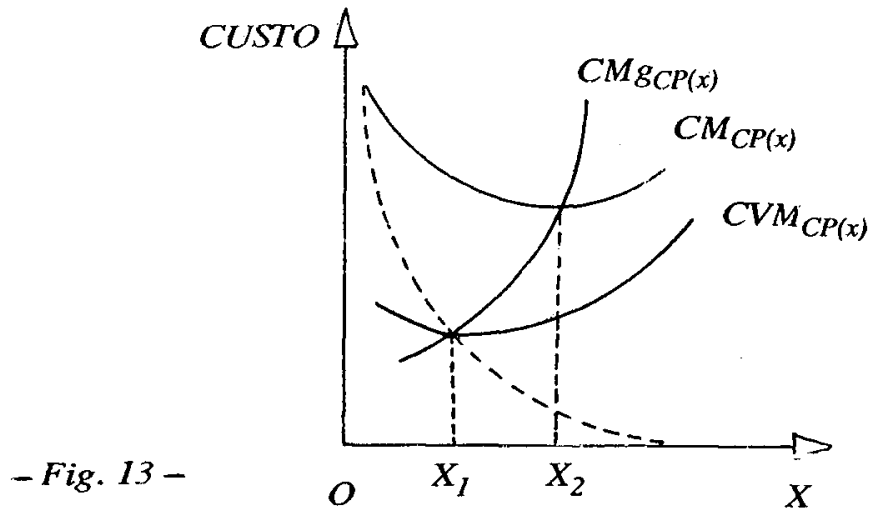

O custo fixo médio (CFM), graficamente, ê uma hipérbore retangular. Do porto de vista gráfico, o custo médio variável $C M V_{C P(x)}$ e o custo unitário $\left(C M_{C P(x)}\right)$, são obtidos nela inclinação do raio que parte da origen: e corta cada um dos custos (total e variável). Quanto à curva de $C M g_{C P(X)}$, ela é obtida pelas diferentes tangentes, seja à curva de $C T_{C P(x)}$ ou à de $C V_{C P(x)}$, dado que o CF é representado por urre constante. Então, em suma, a Fig. 12, acima, permite estabelecer:

i) $\operatorname{tg} \alpha=C T_{C P(x)} / X=C N_{C P(x)}$;

ii) $\operatorname{tg} \beta=C V_{C P(x)} / X=C V M_{C P(x)}$; $\mathrm{e}$

iii) $\operatorname{tg} \gamma=\frac{\partial C T_{C P(x)}}{\alpha X}$

Ainda, com relação a Fig. 13, cabe examinar os "porquês" das formas, em adição ao que acima já se disse. Dado o formato da curva de $C T_{C P(x)}$ (em forma de " $S$ " invertido) e a efinição de $C V M_{C P(x)}$ ou de $C M_{C P(x)}$, há um declínio da tangente (tg $\alpha$ e tg $\gamma$, na Fig. 12) até a inflexấo da curva de $C T_{(x)}$, para depois começar a crescer. O declínio da tangente representa o crescimento e declínio da produtividade média do(s) fator(es) variável(eis). No ponto mínimo da curva de $C V M_{C P(x)}$, a planta está sendo operada no seu ótimo (em termos de custo) quanto ao emprego de fatores fixos e variáveis. O mínimo da curva de $C M_{C P(x)}$ e obtido para quantidades maiores do que no $C V M_{C P(x)}$ dado o efeito do CF. Deve ficar claro, que ambas as curvas - a de $C M_{C P(x)}$ e a de $C V M_{C P(x)}$ - refletem a lei das proporções variáveis ou dos rendimentos, primeiro crescentes e, depois, decrescentes do(s) fator(es) variável(eis). 
Dar porque assumem a forma em " $U$ ". Esta mesma forma tem tantem - $C M g_{C P(x)}$. Também ar a forma em " $S$ " inverso do $C T_{C P(x)}$ "obriga" $a$ isto. Assim e que a tangente (tg $\gamma$, na Fig. 12) declina gradualmente até que se torna paralela ao eixo $x(\operatorname{tg} \gamma=0)$. A partir dá, começa a crescer. No primeiro estágio a produtividade marginal do(s) fator(es) variável(eis) é crescente, depois nula, para decrescer a seguir ${ }^{13}$.

Em resumo, no curto prazo, as curvas de $C M_{C P(x), C V M_{C P(x)}}$ e $C M$ $C P(x)$ assumem a forma em " $U$ " devido a lei dos rendimentos năo proporcionais. Esta é a razão fundamental da teoria tradicional dos custos no curto prazo para que aquelas curvas sejam "construrdas" obedecendo a uma forma em " $U$ ". Deste modo, a teoria assim expressa possui perfeita consistência interna. Então, a questão relevante seria discutir a validade ou não da lei dos rendimentos não proporcionais no caso de uma planta de tamanho definido ${ }^{14}$. Ou, pelo menos, mais precisamente $o$ intervalo de rendimento decrescentes do(s) fator(es) variável(eis). Este ponto será retomado na ocasião em que se tratar de teoria moderna dos custos.

\subsubsection{Custos no longo prazo}

Como se sabe, neste prazo, admite-se que todo os fatores se tornem: variáveis. Na teoria tradicional do custo, a curva de $C M_{L P(x)}$ e obtida a partir das curvas de $C M_{C P(x)}$. Cada ponto desta curva de $C M_{L P(x)}$ corresponde a um determinado ponto da curva de $C M_{C P(x)}$. Neste ponto a curva de $C M_{L P(x)}$ e tangente ac mínimo custo ( 6 timo) para produzir um especifico e exclusivo nivel de produção. A Fig. 14 expressa três tamanhos de planta ou três processos produtivos. Pequena $\left(C M 1_{C P(x)}\right)$, média $\left(C M 2_{C P(x)}\right)$ e grande $\left(C M 3_{C P(x)}\right)$. Se, por exemplo, o empresário desejar produzir $\mathrm{X} 2$, escolheria a planta $C M 2_{C P(x)}$. Ao desejar produzir X3, escolheria a maior planta $\left(C M 3_{C P(x)}\right)$.

13 Podem ser estabelocidas as seguintes relaços entre o $\mathrm{CM}_{\mathrm{CP}(\mathrm{x})}, \mathrm{CVM}_{\mathrm{CP}}(\mathrm{x})$ e $\mathrm{CMg} C P(x)$ : a) $C M_{C P(x)}$ ou $C V M_{C P(x)}$ serabo crescentes quando $C M_{C P(x)}$ ou $C M_{C P(x)}\left(C M_{8 C P(x)}\right.$, decrescentes quando doorrer o inverso;

b) quando ${ }^{C} M_{C P(x)}$ ou $C V M_{C P(x)}$ atingem um minimo, $C_{C P(x)}={ }_{C M} g_{C P(x)}$ e $C V M_{C P(x)}=C M g C P(x)$, sendo este crescente.

14 Esta questio, como se recouda, foi levantada por Sraffa 27 e encontra-se no topico 2 do presente trabalho. 


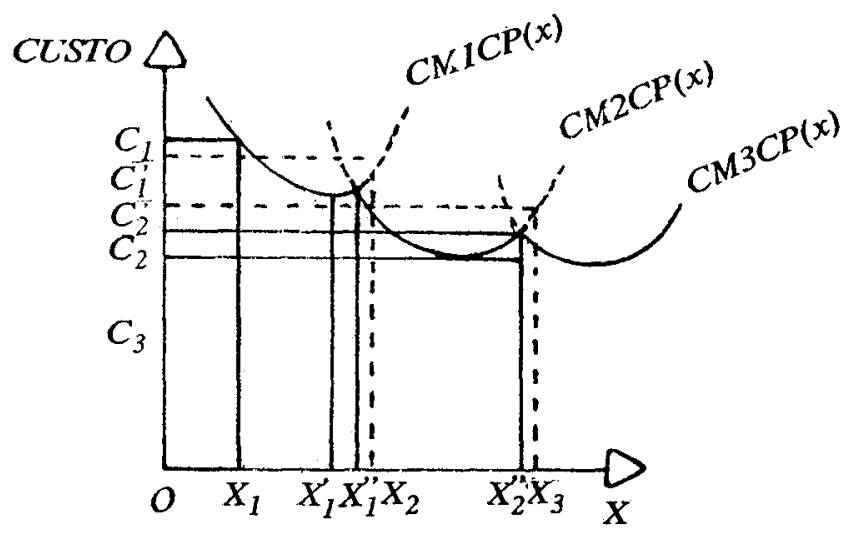

- Fig. 14-

Escolhendo uma planta pequena, o limite mínimo de custo seria em $X_{1}$. Desejando produzir $X^{\prime}{ }_{1}$; qualquer uma das plantas, -pequena ou média, poderá ser escolnida. $O$ que definirá a decisão será a expectativa quanto a demanda. O raciocínio e válido também para $X^{\prime \prime}{ }_{2}$. Admitindose a existência não apenas de três mas de infinitas plantas, cada uma delas viável para cada nível de produto, tem-se uma curva contínua de $C M_{L P(x)}$ (peia existência de infinitas interseçōes entre plantas).

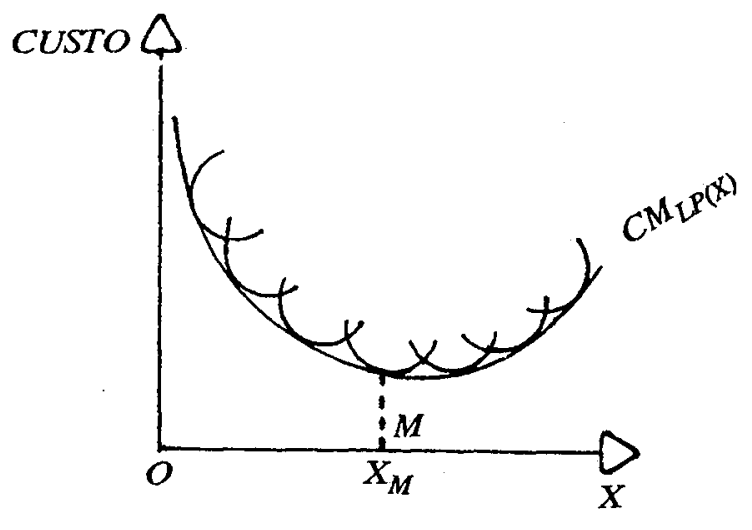

- Fig. 15 - 
Isto $E$ graficamente verificado na Fig. 15. A curva de custo médio a longo prazo é considerada como uma curva de planejamento da empresa. Isto no sentido de que ela orienta o empresário na sua decisão de planejar a expansão de sua produção. Com base nesta curva, o empresário decide qual deve ser a planta para produzir o nivel desejado de produção. Cada ponto dela revela o mfnimo ( 6 timo) custo para produzir o correspondente nfvel de produção. Na teoria tradicional dos custos, a curva de $C M_{L P(x)}$ tem a forma em "U" e é cognominada "curva envelope", por devolver as curvas de $C M_{C P(x)}$. Segundo esta mesma teoria, a forma er. "U" da curva de $C M_{L P(x)}$ reflete a "lei dos retornos de escala". Por esta lei, os custos médios declinam, à medida que aumenta o tamanho da planta, devido às economias de escala da empresa, as quais são permitidas pelas grandes plantas. Desse modo, a partir de dado tamanho ótimo de planta todas as economias possíveis são alcançadas. Portanto, um incremento da planta além deste ótimo, provoca deseconomias de escala. Tal ocorreria em razâc das ineficiências administrativas (complexidades das administrações de grande porte). Traficamente este fenômeno fica expresso pelo aclive da curva de $C M_{L P(x)}$, após atingir um mínimo. Por seu turno, as deseconomias técnicas, estas podem ser evitadas, por exemplo, pela duplicação do tamanho da planta ótima.

Uma questão relevante na teoria tradicional dos custos é que, implicitamente, admite-se cada planta ccmo projetada para produzir, um único nfvel de produção. Assim, cada uma delas é absolutamente inflexível no sentido de manter o menor custo para increrento de produção. Apenas no ponto mínimo da curva de $C M_{L P(x)}$ é que corresponde a um mínimo na curva de $C M_{C P(x)}$. Graficamente, localiza-se no ponto $M$ da Fig. 15. Neste ponto, a planta estaria otimamente empregada. Nos demais, os mf́ninios são somente de curto prazo, não de longo prazo. Então, a esquerda do Ponto $M$ (parte declinante da curva de $C N_{\perp}^{\prime} P(x)$ as plantas não estariam trajalhando com plena capacidade; à sua vez, a direita de $M$ as plantas estariam sobre-ocupadas. Portanto, em ambos os trechos, trabalhar-se-ia com custo alem do btimo. Claro, o primeiro, reflete as economias e, o segundo, as deseconomias de escala.

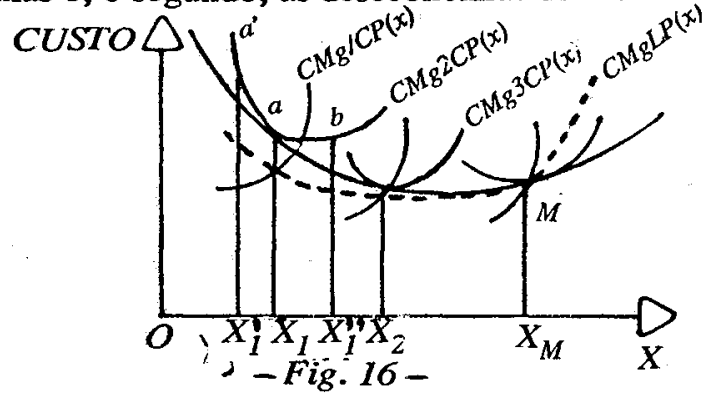


A curva de $C M g_{L P(X)}$, por seu turno, é obtida a partir das curvas de $C M g_{C P(x)}$. Graficamente, ela é formada pelos pontos de intersecção das curvas de $C N g_{C P}$ corr a ordenada que parte de cada nível de produção e atinge a curva de $C M_{L P(x)}$, comc é expresso na Fig. 16. No ponto a (onde o $C M{ }_{C P}$ é mínime), o $C M g_{C P(x)}=C M g_{L P(x)}$. Em a' $\left\langle\mathrm{CMg}_{L P}\right.$. Em b, ou qualquer ponto z direita de a, $\left.C M g_{C P(x)}\right) C M g_{L P(x)}$. Repetidos os procedimentos para obtenção do $C M g_{L P(x)}$ em todos os pontos de tangência da curva de $C M_{L P(x)}$ às curvas de $C M_{C P(x)}$, à esquerda de $M$ na Fig. 16, a curva de $C N g_{L P}$ se localizará abaixo da curva de $C N_{L P(x)}$. Em $M$ (ponto de 6 timo), elas tornam-se exatamente iguais. Já para nf́veis de produção além de $X_{M}$ (portanto, à direita de $M$ ), a curva de $C M^{\prime} g_{L P(x)}$ cresce a taxas mais elevadas do que o $C M_{L P(x)}$, se localizando entao, acims do $C M_{L P(x)}$. O formato tambem em "U" da curva de $C M g_{L P(x)}$, obedece às mesmas razóes que norteiam a forma da curva de $C M_{L P(x)}$, ou seja, devido a "lei dos retornos de escala", a qual já foi referida acime.

Em conclusão, a teoria tradicional dos custos postula a forma em " $U$ " das curvas de cữsto médio e marginal por duas razôes. A primeira, no curto prazo, mantido constante pelo menos um fator, os rendimentos, primeiro crescentes (custo decrescentes) e depois decrescentes (custo crescente) decorrem da desproporção no emprego do(s) fator(es) variável(eis) em relação ao(s) fixo(s). A segunda, no longo prazo, a forma em "U" daquelas curvas é explicada pela "lei dos retornos de escala", no primeiro segmento da curva de $C M_{L P(x)}$ (decrescente) e, pelas deseconomias gerenciais, no segundo trecho (crescente).

É digno de nota, não olvidar a este propósito as restrições de Sraffa (1982) referidas ao infcio do tópico dois, bem como as de Guimarães (1983). Ambos colocam a questão de que a forma em " $U$ ", inclusive de curva de $C N_{i} C P(x)$ \& antes uma condição de equillbrio determinado no modelo de concorrência perfeita do que um pressupos̀to real do sistema produtivo. Além disto, é irreal também nesta teoria a decisão em torno de uma planta corppletamente inflexfvel, sem nenhuma reserva de capacidade. Este suposto implicaria, então, a existência de apenas um ótimo, com respeito ao custo mínimo.

Algumas das questōes colocadas acima e outras são abordadas pela chamada teoria moderna dos custos. Por isto é que segue-se o exame dos custos, através deta teoria.

\subsection{As formas das curvas de custo na teoria moderna: crfticas, propostas e adequaçōes ao mundo real}

\subsubsection{Os custos no curto prazo}


As restrições quanto às formulações da teoria tradicional dos custos começam, na teoria moderna, pela questão da definição da planta que diz respeito ao curto prazo. Definir a mágnitude de uma planta, concretamente, corresponde a definir o tamanho dos fatores indiretos ou fixos (os quais implicam custos fixos, conforme conceituados anteriormente). Quanto aos chamados fatores diretos (os quais implicam custos variáveis, como por exemplo materia-prima e mão-de-obra), admite-se que a empresa os obtenha no mercado em um pequeno lapso de tempo. Por isto, o empresário planejará o tamanho de sua planta de acordo com c nível de produção que ele espera vender, com o menor custo e com o máximo de flexibilidade quanto ao nível de produção, para adequar-se a variações de qualquer ordem da demanda. Em conseqüência, admite-se que o tamanho da planta deve ter uma capacidade maior que a "m€:dia esperada" de vendas. Esta capacidade de reserva irá permitir eventuais sazonalidades ou acrescimos de demanda. Ela pode ser expressa na compra de equipamentos maiores do que a "media esperada de vendas", por estrita disponibilidade no mercade ou por reservas em ediffcios ou terras (no caso da indústria e tambéł na nagricultura). É possível que haja também uma reserva quanto à administração e à gerência.

Estabelecidos estes pressupostos realistas pela chamada roderna teoria dos custos, as curvas de custo médio no curto prazo teriam as conformações abaixo.

A curva de $C F M$ terá a mesma formatação da teoria tradicional (Fig. 17).

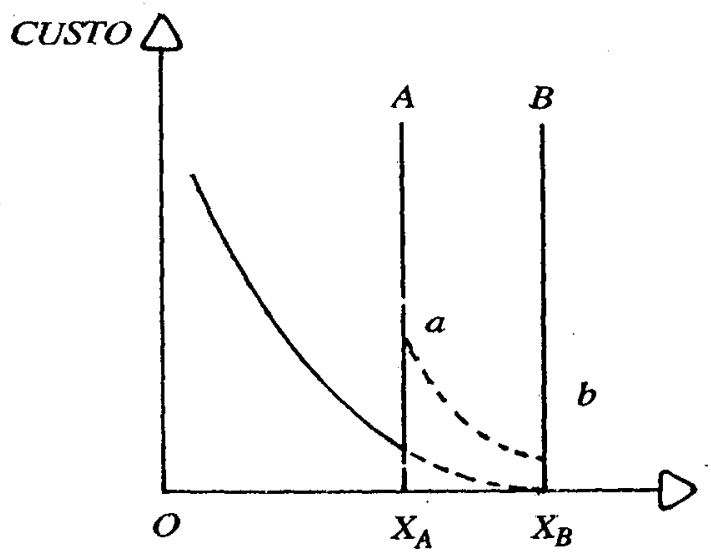

-Fig. 17- 
Suponha-se que uma empresa possua simultaneamente duas plantas15. Um planta maior cujo limite superior de produção e B; uma planta menor cujo limite também superior é A. A, no entanto, não se constitui €m um limite absoluto, pois turnos extras de mão-de-obra podem ser utilizados. Nesta circunstância, a curva de CFM passa a ser a linha pontilhada ab. Alternativamente, com o uso de pequenas máquinas adicionais, a curva de custo fixo médio muda para o segmento tracejado ab.

Por seu turno, o $C V M_{C P(x)}$, nesta teoria (en função aos supostos realistas colocados anteriormente), tem a forma de um pires, denotando um intervalo de produção em que o custo variável médio é constante (Fig. 18). Este intervalo reflete a decisão fixada em uma planta com reserva de capacidade.

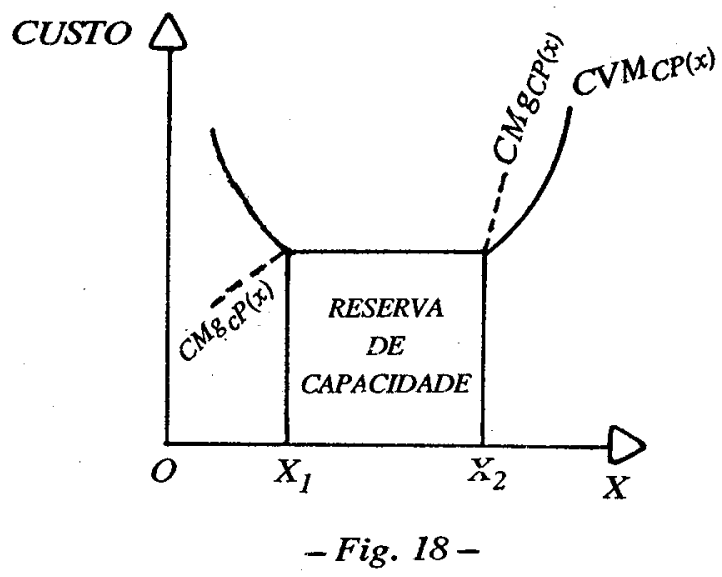

Como se viu acima, esta reserva de capacidade é planejada com finalidade de permitir maior flexibilidade de operação da empresa. Contrariamente à moderia teoria dos custos, a teoria tradicional, ao admitir a curva de $C V M_{C P(x)}$ em forma de "U", postula uma planta ótima para um único nível de produção, vale dizer sem nenhuma flexibilidade. Tal situação implicaria custos maiores para nfveis de produção diferentes do ótimo (menor custo variável médio). A flexibilidade maior de operação, na teoria moderna, permite que a empresa "transite" no intervalo, por exemplo $X_{1} X_{2}$ (Fig 18), sem que isto implique nenhum acréscimo de custos médios. Admite-se que a empresa considere "normal" a utilização de 2/3 a 3/4 de sua planta máxima (Koutzoyanis/1977). Este nivel de utilização é cognominado fator de carga.

\footnotetext{
15 É conveniente notar que há sempre o suposto de que uma planta maior incorra em custo menores, pelo menos a partir de certo nivel de produçæ̌̆o.
} 
No intervalo de $C V M_{C P(x)}$ constante, o $C M g_{C P(x)}=C V M_{C P(x)}$. No trecho declinante da curva de $C V M_{C P(x)}$, o $C N g_{C P(x)} \backslash C V M_{C P(x)} ;$ nC ascendente, ocorre o inverso.

Analogamente à teoria tradicional do custo, a moderna teoria, explica o declínio da curva de $C V M_{C P(x)}$ em razão da adequação do emprego de fator(es) variável(eis) ao(s) fator(es) fixo(s). Adicionalmente também é explicada pela me:lhor perícia da mẽo-de-obra. Vale dizer é umé explicação decorrente da especialização do trabalho. Quanto ao trecho crescente, ele reflete a diminuição da produtividade decorrente do pagamento de horas extras, o desperdício de matérias-primas e a fadiga cc.s equipamentos devido ao uso excessivo. Como se pode perceber, esta explicação na teoria moderna não faz referência a "lei dos rendimentos ñ̃o proporcionais" dcs fatores variáveis como na teoria tradicional dos custos.

O custo médio total $\left(C M_{C P(x)}\right)$ é obtido pela adição de $C V M_{C P}$ ao $C F M$. A curva de $C M_{C P(x)}$ (Fig. 19) declina de rodo contínuo até o limite superior $\left(X_{2}\right)$. A partir de então começa a crescer. A Fig. 19 expressa, de modo conjunto, o conjunto dos custos médio e marginal.

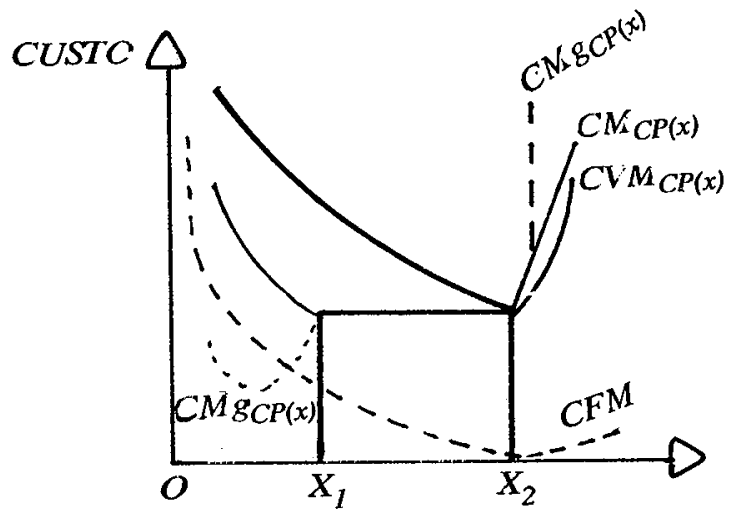

$-F i g .19-$

Os custos totais são expressos graficamente pela Fig. 20 e compreendem apenas o trecho $X_{1} X_{2}$ (Fig. 19), denotando o segmento relevante (limite mínimo e máximo de capacidade, orce o $C V^{\prime} M_{C P(x)}$ é constante). Aliás, $\mathcal{E}$ interessante notar que estas formas de custo sao exatamente iguais às utilizadas pelos especialistas em contabilidade. 


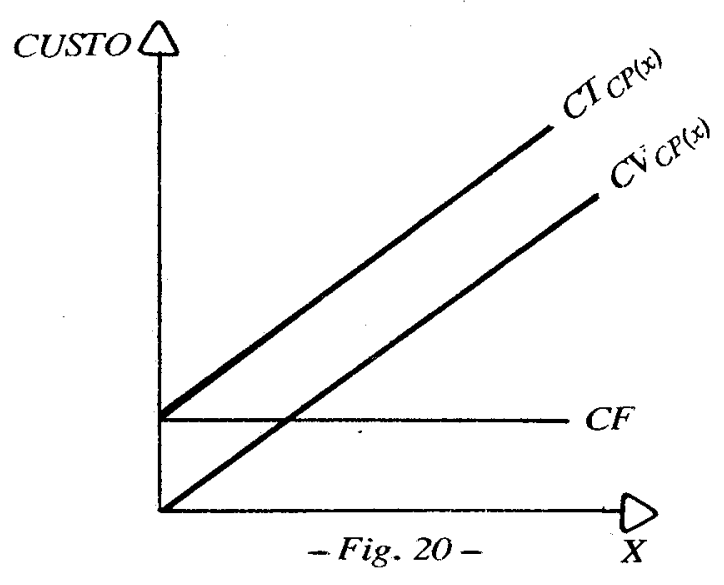

Em conclusão, vale registrar que a exemplo da colocação de Sraffa (referida no tópico dois do presente trabalho), aceitar a forma em pires da curva de $C V M_{C P(x)}$ e o formato da curva de $C M g_{C P(x)}$, implica admitir que a curva de oferta nẽo pessua inclinação positiva, o que derruba por terra a simetria oferta-demandz do mercado de concorrência perfeita.

Esta situação, cortudo, é bastante méis adequada à realidade à medida que o munco real apresenta predominantemente estruturas de mercado oligopolizadas.

\subsubsection{Os custos de longo prazo}

Ao contrário da forma em " $U$ " da curva de $C V M_{L P(x)}$ na teoria tradicionai, a chamada moderna teoria dos custos postula (inclusive por evidências empíricas) que esta term: a forma aproximada de um " $L " . ~ O u$ seja, os custos variáveis médios caer: continuamente com acrescimos no nível de produção para depois mantere m-se constantes. Como se trata do longo prazo, é óbvio, todos os fatores tornam-se variáveis. Então os custos variáveis médios ao carrem inicalmente de modo violento explicam-se pelas econorrias técnicas de grande escala. Estas são atingidas após a emipresa alcançar a escala ótimé mónima para dada tecnologia.

A questão dcs custos gerenciais para a tecria moderna dos custos tem por base a ciência moderna de gerência. Por esta, a cada tauranho de planta decorre uma estrutura administrativa-gerencial adequada. Portanto, existem técnicas de gerência para qualquer tremanho de planta.

Por esta razão, as deseconomias de escala explicadas pela teoria tradicional dos custos $\left(C V M_{C P}\right.$ em forma de " $U$ ") ficam sem sentidc. 
Estabelecidas estas considerações básicas iniciais, vai-se examinar como, formalmente, são obtidas as curvas de longo prazo.

Suponha-se quatro tamainhos de plantas de custo médio a curto prazo (quatro processos produtivos, dada a tecnologia disponfvel). Estas plantas são $C M 1_{C P(x)}, C M 2_{C P}, C M 3_{C P}$ e $C M 4_{C P}$, indicadas pela Fig. 21 . Cada uma delas evidencia o decrescimo de custos à medida que aumenta o tamanho da planta. Como já se referiu acima, cada planta corresponde a um nfvel flexível de produção o qual geralmente pela "expectativa de vendas" determina um certo fator de carga (em torno de $2 / 3$ a $3 / 4$ da capacidade). Este fator representa o uso médio da capacidade, inferior, $€$ claro, ao limite máximo.

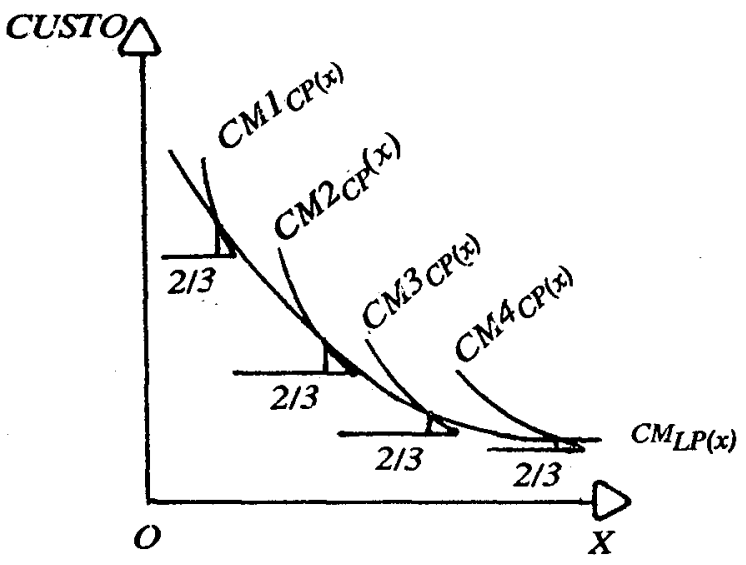

-Fig. $21-$

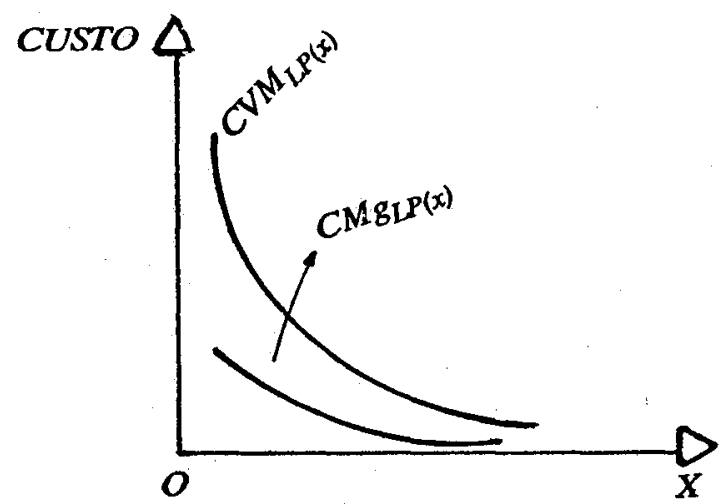

-Fig. $22-$ 


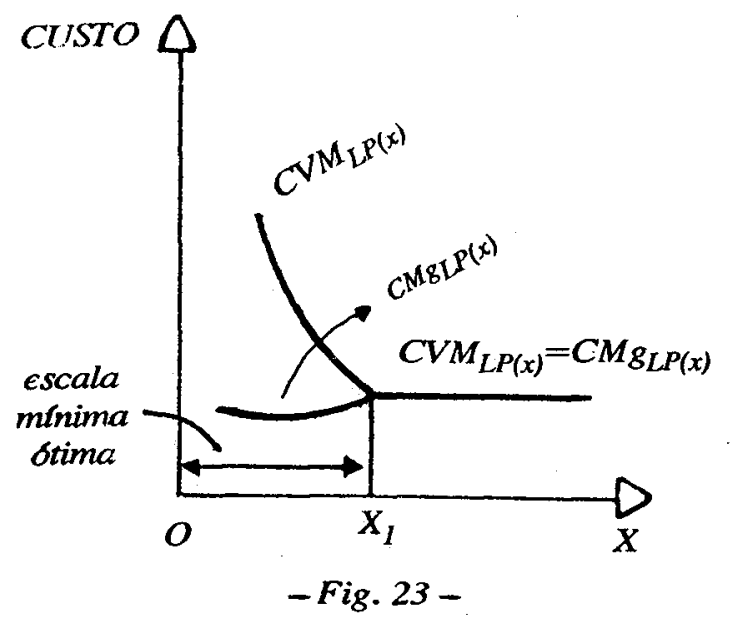

Assim, o que é relevante em cada curva de $C V M_{C P(x)}$ e o trecho de custos constantes e, neste, o ponto que define o fator de carga. Em conseqüência, a curva de $C V M_{L P(x)}$ tamberm chamada de curva de escala será formada por estes pontos. Ao supor-se que haja um grande número de tamanhos de planta, a curva de escala $\left(C V M_{L P(x)}\right.$ será contínua conforme a Fig. 21 estabelece.

Outro conceito usual e o de $C M g_{L P}$. No trecho em que declina a curva de escala, o $C M_{L P(x)}$, sempre se localizará abaixo daquela (Fig. 22). No caso em que a escala ótima é atingida, o $C M g_{L P}$ iguala-se a curva de escala (fig. 23) ${ }^{16}$.

\section{CONCLUSŌES}

Em conclusão, pode-se afirmar que a moderna teoria dos custos e mais adequada para compreender o mundo real ${ }^{17}$ do que aquela que postula as curvas de custo medio em forma " $U$ ". Isto fundamentalmente porque:

a) admite que a empresa pode minimizar seus custos dentro de um

16 Um outro tipo de curvas săo as que têm origem nas funçঠes de produçăo de engenharia. Elas se caracterizam por um númeı limitado de processos produtivos pelo fator de que os fatores săo substiturveis de modo descontínuo e limitado. E póssfvel demonstrar que as funçles custo dal derivadas possuem a forma das funclio-custo da teoría modema dos custos Sto

- todavia abordadas no ambito do presente trabalho. A este propósito, veja-se Koutzoyannis (1977).

17 Isto devido a evidencias demonstradas em diferentes tipo de estudo, conforme aseve: ram Koutzoyannis (1977), p. 137-150 e Bain (1963), p. 175-176. 
intervalo de produção que permite adequar-se às contirgências de mercado;

b) ao formatar a curva de escala em: "L" aceita os rendimentos de: escala, mas rejeita, pelo menos, as deseconomias de escala $\epsilon$ :n nfvel gerencial, o que é uma evidência emṕrica, dada a existência dós granởes conglc merados e mercados oligopolizados.

\section{BIBLIOGRAFIA}

BAIN, J.S. Organización Industrial, Barcelona, Omega, 1963.

DOBRININ, V. Economia Organización y Planificación de la Producción Agropecuaria. Moscu, Progresso, 1992. 474 p.

FIALHO, I.P.M. \& MAIA, M.M. Tamanho de Propriedade e Eficiência na Ágricultura Paulista: o que os censos mostram. Revista de Economia rural, v.21, n.1, p.99-115, jan./mar. 1983.

FoURASTIER, J. Productivite Prix et Salaires. Paris, Organisation Européenne de Cooperation Economique, $1960,115 \mathrm{p}$.

GUIMARĀES, E.A. Curvas de Custo - Economias de Escala. Rio de Janeiro, UFRJ/FEA, 1983, 23 p.

HALL, B.F. \& LEVEEN, E.P. Farm Size and Economic Efficency: the case of California. American Journal of Agricultural Economics. v. 60, n.4, p.589-600 nov., 1978.

KALECKI, M. Teoria da Dinlmica Economica. Os Economistas. Săo Paulo, Abril Cultural, 1983.

KOUTZOYYANIS, A. Modern Microeconomics.London, MacMillian, 1977. 581 p.

LANCASTER, K. Teoria Microeconómica. Rio de Janeiro, Forum, 1972, 2 v.

LIMA, L.A. de Oiveira. O Conceito de Capital e a Distribuiçäo da Renda. Re vista de Administraçio de Empresas. v.14, n.2, p.7-20, mar./abr. 1974.

SIMONSEN, M.H. Teoria Microeconómica. 2. ed. Rio de Janeiro, Fundaçäo Cetúlio Vargas, 1971.2 v.

SRAFFA, P. As leis dos Rendimentos sob Condiçбes de Concorrencia. Literatura EconomiCa, Rio de Janeiro, v.4, n. 1, p.13-34, jan./fev. 1982.

TOLIPAN, R. \& GUIMARÃ É, E.A.A. Uma Nota Introdutória ao Artigo “As Leis do Rendimento sob Condição de Concorréncia", de Piero Sraffa. Literatura Económica, Kio dé Janeiro, v.4, n.1, p.5-11, jan $/$ fev. 1982.

UNIÃO EAS REPÚBLICAS SOCIALISTAS SOVIÉTICAS. Planificación de la Economfa Nacional. Moscí, Progresso, 1981. 295 p.

\section{ABSTRACT}

\section{ECONOMIES OF SCALE: A COMPARATIVE STUDY ON TRADITIONAL AND MODERN COST THEORIES AND ITS ADEQUACY TO THE REAL WORLD}

This paper studies the concept of economies of scale and its association $n$ ith the production function, productivity etc., as well as the available theories of the types of cost curves. The study concludes that the modern theory of costs is more adequate to explain the real world, because the firm can minimize its costs within an interval of production, allowing more flexibility due to market contingencies. 